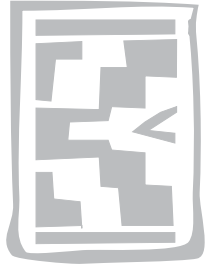

\title{
Prevalence and determinants of Cryptosporidium spp. infection in smallholder dairy cattle in Iringa and Tanga Regions of Tanzania
}

\author{
E.S. SWAI ${ }^{1 *}$, N.P. FRENCH², E.D. KARIMURIBO ${ }^{3}$, J.L. FITZPATRICK ${ }^{4}$, M.J. BRYANT5 ${ }^{5}$, \\ D.M. KAMBARAGE ${ }^{3}$ and N.H. OGDEN ${ }^{6}$
}

\begin{abstract}
SWAI, E.S., FRENCH, N.P., KARIMURIBO, E.D., FITZPATRICK, J.L., BRYANT, M.J., KAMBARAGE, D.M. \& OGDEN, N.H. 2007. Prevalence and determinants of Cryptosporidium spp. infection in smallholder dairy cattle in Iringa and Tanga Regions of Tanzania. Onderstepoort Journal of Veterinary Research, 74:23-29

The prevalence of Cryptosporidium spp. infection in a cross-sectional study of dairy cattle, from two contrasting dairying regions in Tanzania, were determined by staining smears of faecal samples with the modified Ziehl-Neelsen technique. Of the 1126 faecal samples screened, 19.7\% were positive for Cryptosporidium spp. The prevalence was lower in Tanga Region than in Iringa Region. The prevalence of affected farms was $20 \%$ in Tanga and $21 \%$ in Iringa. In both regions, the probability of detecting Cryptosporidium oocysts in faeces varied with animal class, but these were not consistent in both regions. In Tanga Region, Cryptosporidium oocysts were significantly more likely to be found in the faeces of milking cows. In Iringa Region, the likelihood that cattle had Cryptosporidium-positive faeces declined with age, and milking cattle were significantly less likely to have Cryptosporidiumpositive faeces. In this region, $7 \%$ of cattle were housed within the family house at night, and this was marginally associated with a higher likelihood that animals had Cryptosporidium-positive faeces. Our study suggests that even though herd sizes are small, Cryptosporidium spp. are endemic on many Tanzanian smallholder dairy farms. These protozoa may impact on animal health and production, but also on human health, given the close associations between the cattle and their keepers. Further studies are required to assess these risks in more detail, and understand the epidemiology of Cryptosporidium spp. in this management system.
\end{abstract}

Keywords: Cryptosporidium, dairy cattle, epidemiology, Iringa, prevalence, Tanga, Tanzania

* Author to whom correspondence is to be directed. E-mail: emasw@yahoo.co.uk

1 Veterinary Investigation Centre, Box 1068, Arusha, Tanzania

2 Epicentre, Institute of Veterinary, Animal and Biomedical Sciences, College of Sciences, Massey University, Palmerston North, New Zealand

3 Department of Veterinary Medicine and Public Health, Faculty of Veterinary Medicine, Sokoine University of Agriculture, Morogoro, Tanzania

4 Moredun Research Institute, Pentlands Science Park, Bush Loan, Penicuik, UK

5 Department of Agriculture, University of Reading, UK

6 Groupe de Recherche en Épidémiologie des Zoonoses et Santé Publique, Faculté de Médecine Vétérinaire, Université de Montréal, Canada

Accepted for publication 15 September 2006-Editor

\section{INTRODUCTION}

Cryptosporidium is an apicomplexan protozoan causing intestinal infections and clinical disease in both humans and animals worldwide (Fayer \& Ungar 1986; Ramirez, Ward \& Sreevatsan 2004). There is evidence for host association of different species of Cryptosporidia. Cryptosporidium hominis (formerly Cryptosporidium parvum genotype 1) is human-specific and maintained in human-to-human transmission cycles, while Cryptosporidium parvum (formerly Cryptosporidium parvum genotype 2) is maintained by a number of different animal reservoir host species including bovines (Xiao, Fayer, Ryan \& Upton 2004). Cryptosporidium parvum also causes disease in humans and is, therefore, a zoonosis that is trans- 
mitted from cattle to humans. For some bovine-associated species, such as $C$. andersoni, there is no evidence to date for associations with infections or disease in humans(Xiao etal.2004). Cryptosporidium infections are transmitted by the faeco-oral route, and infections in livestock can be transmitted to humans by direct contact and by faecal contamination of drinking water (Ramirez et al. 2004). The disease is readily transmissible, as oocysts persist for long periods in a suitable environment (Castro-Hermida, Gonzalez-Losada \& Ares-Mazas 2002), and low numbers of oocysts may produce infection in susceptible hosts (Ramirez et al. 2004). Enteric disease caused by Cryptosporidium spp. is usually self-limiting in immunocompetent individuals but debilitating and persistent in those immunocompromised (Ramirez et al. 2004). Cryptosporidium infection has been termed as an AIDS-defining illness, and its prevalence amongst AIDS sufferers in Africa is sometimes high (Gatei, Greensill, Ashford, Cuevas, Parry, Cunliffe, Beeching \& Hart 2003). Human infections in Africa have been associated with C. parvum (Tumwine, Kekitiinwa, Nabukeera, Akiyoshi, Rich, Widmer, Feng \& Tzipori 2003), which may be of livestock origin because Cryptosporidium spp. infections in livestock appear to be common (Matovelo, Landsverk \& Posoda 1984; Esrony, Kambarage, Mtambo, Muhairwa \& Kusiluka 1996; Mtambo, Sebatwale, Kambarage, Muhairwa, Maeda, Kusiluka \& Kazwala 1997).

Smallholder dairy production is now a widespread practice in East Africa, having received support for agricultural development and improved standards of living, as well as being a system that may improve human nutrition (Mdoe 1993; Thorpe, Chabari, Maloo, Muinga, Mukhebi, Mullins, Muriethi, Mussukuya, Nyambaka, Ole-maki, Otieno, Perry, Rugema \& Wekesa 1993). In this study we have investigated the prevalence of Cryptosporidium spp. infections amongst smallholder dairy cattle in two regions of Tanzania. We have also attempted to investigate potential risk factors for infection in these cattle that may point to methods by which infections can be controlled and/or their transmission to humans limited.

\section{MATERIALS AND METHODS}

\section{The study area}

The study sites are described in detail in Ogden, Swai, Beauchamp, Karimuribo, Fitzpatrick, Bryant, Kambarage \& French (2005). Briefly, the study was carried out in two regions of Tanzania, namely the coastal Tanga Region, that lies between $38-39^{\circ} \mathrm{E}$ and $4-6^{\circ} \mathrm{S}$, and the inland highland Iringa Region, lying between $35-36^{\circ} \mathrm{E}$ and $7-8^{\circ} \mathrm{S}$. The study took place in two of the six administrative districts in Iringa Region (Iringa urban and Iringa rural, now Kilolo), and five of the six administrative districts in Tanga Region (Korogwe, Lushoto, Muheza, Pangani and Tanga).

\section{Study farm selection}

Farms in each study region were randomly selected by means of the random number generator in EpiInfo version 6 (CDC, Atlanta, USA), from a sampling frame of 3001 in Tanga and 500 in Iringa using the databases of the Tanga and Iringa Dairy Development Projects. Farms at both study sites were estimated to have an average of three to four dairy animals of any age and both sexes, therefore a farm sample size of 200 in each study region was considered necessary to provide between 600 and 800 animals. The sample size in each region was calculated to provide $80 \%$ ability to detect an odds ratio of 2.0 , assuming a critical probability of 0.05 , and exposure that occurs in $50 \%$ of the population, a prevalence of $20 \%$ in the unexposed group and a design effect of 2.0 (French \& Tyrer 1997). Farms recorded to have more than ten animals were excluded from the selection process because farms of this size are not considered as 'smallholder' farms (Tanga Dairy Development Programme 1999), although a small number of selected farms had more than ten cattle by the time sampling began.

\section{Study animals}

The population of interest consisted of all smallholder mixed dairy farmers and dairy cows from the five administrative districts of Tanga and two of the Iringa study regions. A 'dairy animal' referred to crosses of Bos taurus cattle (mainly Ayrshire, Friesian and Jersey) with the Bos indicus breed, the indigenous Tanzania short horn zebu (TSHZ) or Boran. The level of exotic blood varied from first to third filial generation (F1, F2 and F3). The animal husbandry practices included both zero and open grazing systems. Over $60 \%$ of the cattle were stall-fed throughout the year.

\section{Data collection}

Data were collected from farms by two separate teams of researchers, one in each region. Faecal sampling and data collection were carried out between January and April 1999. One person in each region collected farm- and animal-level data on a 
structured questionnaire, which was completed on all selected farms on a single visit. The information collected concerned farm and animal events that occurred during 1998, including the numbers of animals that had died or suffered ill health on each farm (not reported here), parasite control, feeding methods and feed types, cattle movements on and off the farm, and grazing and housing practices. The response to many of these questions were investigated as explanatory variables in analysis of positivity/negativity for Cryptosporidium spp. infection. These included variables that could be considered as farm-level variables including 'farm class' (whether the farm was located in an urban, rural or periurban area), frequency of contact with extension officers (rare, moderate or intensive) and farmer attendance at a Dairy Development Project training course. Animal housing details, including building, flooring and bedding types, were recorded and used as explanatory variables in statistical analyses. The administrative district in which the farm occurred was also considered as an explanatory variable in the analysis.

Animal-level variables included age (centre), sex, breed, filial generation, source (homebred or broughtin), source of brought-in animals (charity gift, dairy development project credit agreement, or cash purchase), whether or not the animal had been zerograzed or allowed to graze at pasture in the three months prior to the onset of the sampling period (October to December 1998), and anthelmintic treatments during this period. Factorized 'classes' of adult female animals were also created as follows: pregnant cows (all females that have had one calf and were pregnant at the time of the visit), milking cows (all females that were in milk at the time of the visit), and 'dry cows' (cows that were not in milk, nor pregnant at the time of the visit).

\section{Laboratory analysis of samples}

During the visit to each farm, a fresh rectal faecal sample was collected from each animal into a sterile, airtight, $10 \mathrm{~m} \ell$ plastic tube. Collected faecal samples were labelled and transported in a cool-box to local laboratories prior to despatch in refrigerated containers to Sokoine University of Agriculture in Morogoro. Here, the presence of Cryptosporidium spp. oocysts in faeces samples was detected using the modified Ziehl-Neelsen staining technique as described by Henriksen \& Pohlenz (1981). Briefly, faecal smears were prepared on a microscope slide, air dried and fixed with methanol for $5 \mathrm{~min}$. Fixed smears were stained with dilute carbol fuchsin (1:10) for 3-5 min and washed with tap water. Smears were decolourized using acid alcohol, then counterstained with $0.5 \%$ malachite green solution for $1 \mathrm{~min}$. Smear slides were air dried and then examined under the microscope at 400x magnification. Cryptosporidium spp. oocysts appear as pink to red, spherical to ovoid bodies against a green to purple background. Samples were considered positive if at least one morphologically distinct Cryptosporidium spp. oocyst was observed.

\section{Statistical analysis}

Data files of questionnaires and laboratory results were prepared in Epi-Info version 6.04b (CDC, USA). The presence or absence of oocysts in faeces samples was the outcome variable in mixed effects logistic regression analyses performed in STATA version 6 for Windows (STATA Corporation, College Station, Texas, USA). The animal- and farm-level variables described above served as explanatory variables. Associations between explanatory variables and the outcome were investigated singly and in multivariable models. In multivariable models, backwards and forwards substitution and elimination were performed to find the most parsimonious model from which no explanatory variables could be removed without significantly affecting model deviance. Cross tabulations and correlations were performed on explanatory variables to identify highly associated variables that could not be incorporated in the same multivariable models. In all models, the farm identification (ID) number was considered a random effect to account for clustering of animals by farm, and the level of significance was $P<0.05$ throughout. Separate statistical analyses were performed for the data from the two regions because previous studies have indicated that parasite ecology and epidemiology may be very different in the two regions (Ogden et al. 2005; Swai, French, Karimuribo, Fitzpatrick, Bryant, Brown \& Ogden 2005).

\section{RESULTS}

\section{Farm response rate}

All selected 200 farms from each of Tanga and Iringa Regions were visited during the period of January to April 1999. In Tanga, a total of 697 animals kept on 185 farms $(92.5 \%$ of the sample) were examined and sampled. Fifteen farms $(7.5 \%)$ had no animals during the actual survey period. In Iringa, a total of 698 animals from 195 farms ( $97.5 \%$ of the sample) were examined and sampled. Three farms $(1.5 \%)$ had no animals and animals on two farms (1\%) could 
Cryptosporidium spp. infection in smallholder dairy cattle in Tanzania

TABLE 1 The proportions of cattle in each category of each variable investigated during the study

\begin{tabular}{|c|c|c|c|}
\hline \multirow{2}{*}{ Variable } & \multirow{2}{*}{ Categories } & \multicolumn{2}{|c|}{ No. of animals (\%) } \\
\hline & & Iringa & Tanga \\
\hline \multicolumn{4}{|l|}{ Animal-level variables } \\
\hline Sex & $\begin{array}{l}\text { Male } \\
\text { Female }\end{array}$ & $\begin{array}{l}182(26) \\
516(74)\end{array}$ & $\begin{array}{l}146(21) \\
551(79)\end{array}$ \\
\hline Source of animal & $\begin{array}{l}\text { Homebred } \\
\text { Brought-in }\end{array}$ & $\begin{array}{l}406(58) \\
292(42)\end{array}$ & $\begin{array}{l}436(63) \\
261(37)\end{array}$ \\
\hline Filial generation & $\begin{array}{l}\text { F1 } \\
\text { F2 } \\
\text { F3 }\end{array}$ & $\begin{aligned} 350 & (50) \\
347 & (49.9) \\
1 & (0.1)\end{aligned}$ & $\begin{array}{c}217(31) \\
459(66) \\
21(3)\end{array}$ \\
\hline Adult cow 'class' & $\begin{array}{l}\text { Milking cows } \\
\text { Dry cows } \\
\text { Pregnant cows }\end{array}$ & $\begin{array}{c}158(22.6) \\
60(8.6) \\
65(9.3)\end{array}$ & $\begin{array}{l}137(20) \\
50(7) \\
86(12.3)\end{array}$ \\
\hline Breed & $\begin{array}{l}\text { Ayrshire cross } \\
\text { Friesian cross } \\
\text { Jersey cross } \\
\text { Simmental cross } \\
\text { Sahiwal cross } \\
\text { TSHZ cross } \\
\text { Boran cross }\end{array}$ & $\begin{array}{c}403(58) \\
305(44) \\
1(0.1) \\
0 \\
0 \\
150(22) \\
549(78)\end{array}$ & $\begin{aligned} & 169(24) \\
& 604(86) \\
& 12(2) \\
& 5(1) \\
& 12(2) \\
& 541(77) \\
& 121(17)\end{aligned}$ \\
\hline Age & $\begin{array}{l}<3 \text { years } \\
3 \text { to }<6 \text { years } \\
>6 \text { years }\end{array}$ & $\begin{array}{r}440(63) \\
165(24) \\
93(13)\end{array}$ & $\begin{array}{r}396(57) \\
214(31) \\
87(12)\end{array}$ \\
\hline Grazing history in last 3 months of 1998 & $\begin{array}{l}\text { Zero grazing } \\
\text { Semi/free grazing }\end{array}$ & $\begin{array}{l}423(61) \\
275(39)\end{array}$ & $\begin{array}{r}626(90) \\
71(10)\end{array}$ \\
\hline Anthelmintic treatment in 1998 & $\begin{array}{l}\text { Yes } \\
\text { No }\end{array}$ & $\begin{array}{r}614(88) \\
84(12)\end{array}$ & $\begin{array}{l}313(45) \\
384(55)\end{array}$ \\
\hline \multicolumn{4}{|l|}{ Farm-level variables } \\
\hline Farm classification & $\begin{array}{l}\text { Peri-urban } \\
\text { Urban } \\
\text { Rural }\end{array}$ & $\begin{array}{l}109(16) \\
391(56) \\
198(28)\end{array}$ & $\begin{array}{l}117(17) \\
318(46) \\
262(37)\end{array}$ \\
\hline Housing details & $\begin{array}{l}\text { Cowshed with roof } \\
\text { Cowshed no roof } \\
\text { Traditional kraal or boma }\end{array}$ & $\begin{array}{r}531(76.1) \\
80(11.4) \\
87(12.5)\end{array}$ & $\begin{array}{c}644(92.4) \\
39(5.6) \\
14(2)\end{array}$ \\
\hline Sleeping area & $\begin{array}{l}\text { Cubicle in cow shed } \\
\text { Cow shed floor } \\
\text { Family house }\end{array}$ & $\begin{array}{c}398(57) \\
247(35.3) \\
53(7.6)\end{array}$ & $\begin{array}{r}374(53.6) \\
315(45.2) \\
8(1.14)\end{array}$ \\
\hline Floor/bedding type & $\begin{array}{l}\text { Concrete } \\
\text { Left over forage } \\
\text { Dried grass } \\
\text { Hardcore } \\
\text { Soil } \\
\text { Wood }\end{array}$ & $\begin{aligned} 335 & (47.9) \\
0 & (0) \\
23 & (3.3) \\
67 & (9.5) \\
201 & (28.7) \\
72 & (10.3)\end{aligned}$ & $\begin{aligned} 402 & (57.6) \\
69 & (9.9) \\
16 & (2.3) \\
38 & (5.4) \\
168 & (24.1) \\
4 & (0.6)\end{aligned}$ \\
\hline Frequency of extension officer contact & $\begin{array}{l}\text { Rare } \\
\text { Moderate } \\
\text { Intensive }\end{array}$ & $\begin{array}{c}15(2) \\
596(85) \\
87(13)\end{array}$ & $\begin{aligned} 6 & (0.8) \\
659 & (94.5) \\
32 & (4.7)\end{aligned}$ \\
\hline District (Iringa) & $\begin{array}{l}\text { Iringa urban } \\
\text { Iringa rural (Kilolo) }\end{array}$ & $\begin{array}{l}461(66) \\
237(34)\end{array}$ & NA \\
\hline District (Tanga) & $\begin{array}{l}\text { Tanga } \\
\text { Muheza } \\
\text { Pangani } \\
\text { Korogwe } \\
\text { Lushoto }\end{array}$ & NA & $\begin{array}{c}341(48.8) \\
185(26.5) \\
26(4) \\
64(9) \\
81(12)\end{array}$ \\
\hline
\end{tabular}

$\mathrm{NA}=$ Not applicable 
TABLE 2 The prevalence of Cryptosporidium spp. in dairy cattle by regions and districts in Iringa and Tanga. $95 \% \mathrm{Cl}=$ confidence intervals adjusted for the farm effect

\begin{tabular}{|l|l|l|}
\hline District & Number of animals positive & \% positive (95\% Cl) \\
\hline Iringa Region & \multicolumn{2}{|l|}{} \\
\hline Iringa rural & $43 / 201$ & $21.3(18.4-25.0)$ \\
Iringa urban & $138 / 481$ & $28.6(26.5-30.9)$ \\
All & $181 / 682$ & $26.5(24.7-28.4)$ \\
\hline Tanga Region & \multicolumn{2}{|}{} \\
\hline Tanga & $24 / 228$ & $10.5(8.6-13.0)$ \\
Muheza & $12 / 134$ & $8.9(5.6-12.2)$ \\
Korogwe & $4 / 38$ & $10.5(8.6-13.0)$ \\
Lushoto & $1 / 33$ & $3.03(0.07-7.7)$ \\
Pangani & $0 / 11$ & $0(0-28.5)$ \\
All & $41 / 444$ & $9.3(7.7-11.0)$ \\
\hline
\end{tabular}

not sampled because the owner could not be traced. The number of animals examined per herd ranged from 1-13 animals. The age range of animals examined varied from 1 day to 13 years. The characteristics of the sample of cattle in each region are detailed in Table 1.

\section{Prevalence of Cryptosporidium spp. oocysts in faeces samples}

Results were available from 444 of the 697 animals sampled in Tanga, and 682 of the 698 animals sampled in Iringa. The missing results arose due to loss of labels during transport to laboratories. Of the 1126 faecal samples screened in both Tanga and Iringa, 222 (19.7\%) were positive for Cyptosporidium spp oocysts. The prevalence amongst study animals investigated was higher in Iringa than in Tanga (Table 2).

In Tanga Region, the highest prevalence was observed in cattle in Tanga, Korogwe, Muheza and least in Lushoto and none in Pangani districts (Table 2 ), although these differences were not significant (likelihood ratio statistic $[\mathrm{LHR}]=4.89, \mathrm{df}=4, P>$ $0.1)$. In Tanga Region, on 37 of the 185 farms sampled $(20 \%, 95 \%$ confidence interval $[\mathrm{Cl}]=14.5-$ 26.5) at least one animal tested positive for Cryptosporidium infection. In Iringa Region, 41 of 195 farms $(21 \%, \mathrm{Cl}=15.5-27.4)$ had at least one animal positive.

In Iringa Region, two factors remained significant in the multivariable model. First, the likelihood that faecal samples were positive decreased significantly with animal age (coefficient $=-0.009, \mathrm{SE}=0.004$, $P=0.017$ ). Second, faecal samples from milking cows were significantly less likely to be positive than those of other classes of cattle (odds ratio [OR] =
$0.56, \mathrm{Cl}=0.32-0.97, P=0.038$ ). Faecal samples from animals that were kept in the family house at night were positive more often than samples from animals housed in other buildings but the difference was not significant $(\mathrm{OR}=1.75, \mathrm{Cl}=0.92-3.34, P=$ 0.09). In Tanga, milking cows were significantly more likely to have positive faeces samples than other animal classes $(\mathrm{OR}=2.19, \mathrm{Cl}=1.08-4.39, P=$ $0.028)$. The random effect of farm ID number was negligible in Tanga Region (coefficient $=0.001$, SE $=0.735$ ), but strong in Iringa Region (coefficient $=$ 0.472, SE $=0.237$ ).

\section{DISCUSSION}

Inthisstudy, there was evidence that Cryptosporidium spp. are endemic on smallholder dairy farms in two different regions of Tanzania. The detected prevalence of infection in the cattle was intermediate in comparison with that observed in other studies in Tanzania, from 5.3\% (Mtambo et al. 1997) up to $62 \%$ (Lema 1990; Esrony et al. 1996). It was generally lower than observed in studies in Europe for instance up to $36 \%$ in dairy cattle in Germany (Joachim, Krull, Schwarzkopf \& Daugschies 2003) and $80 \%$ in calves Britain (Scott, Smith, Mtambo \& Gibbs 1995). While the method of detection used in the present study is a rapid screening method, there was no attempt to concentrate faecal oocysts and the method has low sensitivity of detection compared to other methods (Gobet, Buisson, Vagner, Naciri, Grappin, Comparot, Harly, Aubert, Varga, Camerlynck \& Bonnin 1997). Furthermore, our cross-sectional study would not capture the potential for seasonal variations in prevalence that, in studies in Europe, may be considerable (Huetink, Van der Giessen, Noordhuizen \& Ploeger 2001). 
Our prevalence estimates are likely, therefore, to be lower than the true prevalence in the cattle, but it could be expected that features of cattle demography and management on smallholder dairy farms are not conducive to the maintenance of endemic cycles of Cryptosporidium spp. by the cattle alone. These include the low number of cattle on individual farms, often consisting of just one or two animals, low rates of reproduction amongst the cattle, and a low rate of production of Cryptosporidium-naïve and susceptible calves (French, Tyrer \& Hirst 2001). The mostly zero-grazed management may reduce the potential for farm-to-farm transmission. Despite these features, which could all result in fade-out of infectious diseases (Anderson \& May 1992), Cryptosporidium spp. were detected in faeces of the cattle in nearly all the administrative districts in both regions studied.

There was evidence of geographic variations in the prevalence, and possibly the dynamics of infection. First, the detected prevalence of infection was higher in cattle in Iringa Region than in Tanga Region. This is consistent with unpublished observations for prevalence of infection in other species in Tanzania (dogs, pigs and cattle in other management systems) in which prevalence is generally higher in regions that have a cooler climate, suggesting that the high ambient temperature and humidity in coastal Tanga may be sub-optimal for survival of Cryptosporidium spp. outside the host. Second, the risk factors for infection varied between the two regions. In Iringa Region, younger animals were more likely to be positive, and milking adult cows were particularly unlikely to be detectably infected. In Tanga Region, there was no association of detected infection with age, but milking adult cows were particularly likely to be positive. In addition, the farm effect in Iringa Region was high suggesting that unmeasured management characteristics of individual farms had a considerable effect on Cryptosporidium spp. epidemiology, which was not the case in Tanga Region. This may also suggest that important features of the epidemiology of these infections may differ in the two regions, which could also be associated with differences in climate between the regions. In a study of Cryptosporidium spp. dynamics in cattle of farms in the USA, however, infections in younger animals were associated with the zoonotic C. parvum, while infections in older animals were associated with non-zoonotic species or genotypes (Santin, Trout, Xiao, Zhou, Greiner \& Fayer 2004). Thus our observed regional differences in the epidemiology of Cryptosporidium spp. could possibly signify differences in the risk of human infections.
Our study indicated that smallholder dairy farmers and their families often live in close proximity to their cattle, even within the family home. The probability of transmission of zoonotic Cryptosporidium spp. from cattle to humans on these farms may, therefore, be high. Farmers keep their cattle within the family home at night to prevent the theft of these valuable commodities (Karimuribo, personal communication 2002). It is not clear, however, why the detected prevalence of infection in cattle that are brought into the home at night was particularly high; this warrants further investigation.

In this study we have demonstrated the presence of Cryptosprodium spp. infection in smallholder dairy cattle in two regions of Tanzania. The epidemiology of infection may differ in different regions with potential consequences for human health. Some cattlekeeping practices are likely to enhance direct bovineto-human transmission. Further studies are needed to understand the dynamics of transmission cycles and the genetic diversity of Cryptosporidium spp. on the farms, and to identify and if possible alter management practices that are risk factors for human infections.

\section{ACKNOWLEDGEMENTS}

This study was funded by the UK Department for International Development. We thank all the farmers who participated, and the veterinarians and staff of the Tanga and Southern Highlands Dairy Development Programmes for their very considerable support and assistance. Thanks are extended to the Director of Veterinary Service, Tanzania for permission to publish this work.

\section{REFERENCES}

ANDERSON, R.M. \& MAY, R.M. 1992. Infectious diseases of humans: dynamics and control. Oxford: Oxford University Press.

CASTRO-HERMIDA, J.A., GONZALEZ-LOSADA, Y.A. \& ARESMAZAS, E. 2002. Prevalence of and risk factors involved in the spread of neonatal bovine cryptosporidiosis in Galicia (NW Spain). Veterinary Parasitology, 106:1-10.

ESRONY, K., KAMBARAGE, D.M., MTAMBO, M.A.A., MUHAIRWA, A.P. \& KUSILUKA, L.J.M. 1996. Intestinal protozoan parasites of pigs under different management systems in Morogoro, Tanzania. Journal of Applied Animal Research, 10:25-31

FAYER, R. \& UNGAR, B.L. 1986. Cryptosporodium spp. and cryptosporodosis. Microbiology Review, 50:458-483.

FRENCH, N.P. \& TYRER, J. 1997. Birth and death of cattle on small-scale dairy farms in Zimbabwe. Society of Veterinary Epidemiology and Preventive Medicine, Chester (poster presentation). 
FRENCH, N.P., TYRER, J. \& HIRST, W.M. 2001. Smallholder dairy farming in the Chikwaka communal land, Zimbabwe: birth, death and demographic trends. Preventive Veterinary Medicine, 48:101-112.

GATEI, W., GREENSILL, J., ASHFORD, R.W., CUEVAS, L.E., PARRY, C.M., CUNLIFFE, N.A., BEECHING, N.J. \& HART, C.A. 2003. Molecular analysis of the 18S rRNA gene of Cryptosporidium parasites from patients with or without human immunodeficiency virus infections living in Kenya, Malawi, Brazil, the United Kingdom, and Vietnam. Journal of Clinical Microbiology, 41:1458-1462.

GOBET, P., BUISSON, J.C., VAGNER, O., NACIRI, M., GRAPPIN, M., COMPAROT, S., HARLY, G., AUBERT, D., VARGA, I., CAMERLYNCK, P. \& BONNIN, A. 1997. Detection of Cryptosporidium parvum DNA in formed human feces by a sensitive PCR-based assay including uracil-N-glycosylase inactivation. Journal of Clinical Microbiology, 35:254-256.

HENRIKSEN, S.A. \& POHLENZ, J.F.L.1981. Staining of Cryptosporodia by modified Ziehl-Neelsen technique: a brief communication. Acta Veterinaria Scandinavica, 25:322-326.

HUETINK, R.E., VAN DER GIESSEN, J.W., NOORDHUIZEN, J.P. \& PLOEGER, H.W. 2001. Epidemiology of Cryptosporidium spp. and Giardia duodenalis on a dairy farm. Veterinary Parasitology, 102:53-67.

JOACHIM, A., KRULL, T., SCHWARZKOPF, J. \& DAUGSCHIES, A. 2003. Prevalence and control of bovine cryptosporidiosis in German dairy herds. Veterinary Parasitology, 112:277288.

LEMA, B. 1990. Study of aetiologies of neonatal calf diarrhoea in selected farms in Tanzania. Ph.D. thesis, University of Giessen, Germany.

MATOVELO, J.A., LANDSVERK, T. \& POSODA, G.A. 1984. Cryptosporidosis in Tanzania goat kids, scanning and electron microscopic observations. Acta Veterinaria Scandinavica, 2:322-326.

MDOE, N. 1993. Small holder dairy production and marketing of milk in Hai District, Tanzania. Ph.D. thesis, University of Reading, UK.

MTAMBO, M.M., SEBATWALE, J.B., KAMBARAGE, D.M., MUHAIRWA, A.P., MAEDA, G.E., KUSILUKA, L.J. \& KAZWALA, R.R. 1997. Prevalence of Cryptosporidium spp. oocysts in cattle and wildlife in Morogoro region, Tanzania. Preventive Veterinary Medicine, 31:185-190.

OGDEN, N.H., SWAI, E., BEAUCHAMP, G., KARIMURIBO, E., FITZPATRICK, J.L. BRYANT, M.J., KAMBARAGE, D. \& FRENCH, N.P. 2005. Risk factors for tick attachment to small-holder dairy cattle in Tanzania. Preventive Veterinary Medicine, 67:157-170.

RAMIREZ, N.E., WARD, L.A. \& SREEVATSAN, S. 2004. A review of the biology and epidemiology of cryptosporidiosis in humans and animals. Microbes Infection, 6:773-785.

SANTIN, M., TROUT, J.M., XIAO, L., ZHOU, L., GREINER, E. \& FAYER, R. 2004. Prevalence and age-related variation of Cryptosporidium species and genotypes in dairy calves. Veterinary Parasitology, 122:103-117.

SCOTT, C.A., SMITH, H.V., MTAMBO, M.M.A. \& GIBBS, H.A. 1995. An epidemiological study of Cryptosporidium parvum in two herds of adult beef cattle. Veterinary Parasitology, 57: 277-289.

SWAI, E.S., FRENCH, N.P., KARIMURIBO, E.D., FITZPATRICK, J.L., BRYANT, M.J., BROWN, P.E. \& OGDEN, N.H. 2005. Spatial and management factors associated with exposure of smallholder dairy cattle in Tanzania to tick-borne pathogens. International Journal of Parasitology, 35:1085-96.

TANGA DAIRY DEVELOPMENT PROGRAMME 1999. Annual progress report, Tanga.

THORPE, W., CHABARI, F., MALOO, S.H., MUINGA, R.W., MUKHEBI, A.,_MULLINS, G., MURIETHI, J., MUSSUKUYA, E., NYAMBAKA, R., OLE-MAKI, M., OTIENO, L., PERRY, B., RUGEMA, E. \& WEKESA, E. 1993. Smallholder dairy cattle production in coastal Kenya: resource base assessment and constraint identification. Proceedings of the Meeting on Animal Production in Developing Countries, Ashford, UK, Sept 2-4, 1991, British Society of Animal Production, Penicuik, Scotland, UK: 167-168.

TUMWINE, J.K., KEKITIINWA, A., NABUKEERA, N., AKIYOSHI, D.E., RICH, S.M., WIDMER, G., FENG, X. \& TZIPORI, S. 2003. Cryptosporidium parvum in children with diarrhea in Mulago Hospital, Kampala, Uganda. American Journal of Tropical Medicine Hygiene, 68:710-715.

XIAO, L., FAYER, R., RYAN, U. \& UPTON, S.J. 2004. Cryptosporidium taxonomy: recent advances and implications for public health. Clinical Microbiology Review, 17:72-97. 